\title{
Catalase immunoexpression in colorectal lesions
}

\author{
Adam Piecuch ${ }^{1}$, Józef Kurek², Marek Kucharzewski ${ }^{3}$, Grzegorz Wyrobiec ${ }^{1}$, Dawid Jasiński ${ }^{1}$, \\ Marlena Brzozowa-Zasada ${ }^{1}$ \\ ${ }^{1}$ Department of Histology and Cell Pathology, School of Medicine with the Division of Dentistry in Zabrze, Medical University \\ of Silesia in Katowice, Poland \\ ${ }^{2}$ Department of Surgery, Municipal Hospital, Jaworzno, Poland \\ ${ }^{3}$ Department of Descriptive and Topographical Anatomy, School of Medicine in Zabrze, Medical University of Silesia \\ in Katowice, Poland
}

Gastroenterology Rev 2020; 15 (4): 330-337

DOI: https://doi.org/10.5114/pg.2020.101562

Key words: colorectal cancer, reactive oxygen species, catalase, oxidative stress, antioxidants.

Address for correspondence: Dr Marlena Brzozowa-Zasada, Department of Histology and Cell Pathology, School of Medicine with the Division of Dentistry, Medical University of Silesia, Zabrze, Poland, phone: +48 32272 28 42, e-mail: marlena.brzozowa@op.pl

\begin{abstract}
Introduction: It is generally accepted that the gastrointestinal tract, and especially the colon, is constantly exposed to reactive oxygen species (ROS) that may be responsible for the appearance of genetic mutations. To keep a steady-state control over ROS production-detoxification, organisms have evolved a defensive system. Nevertheless, many reports have described decreased level of antioxidant enzymes, especially catalase (CAT), in cancer tissues.

Aim: In this work we try to assess the immunohistochemical expression of CAT protein in colorectal adenoma and adenocarcinoma samples.

Material and methods: This study was performed on resected specimens obtained from 122 patients who had undergone surgical resection for colorectal cancer, and from 120 patients who had undergone colonoscopy. Paraffin- embedded, $4 \mu \mathrm{m}$-thick tissue sections were stained for rabbit polyclonal anti CAT antibody obtained from GeneTex (cat. no. GTX110704).

Results: In adenoma strong immunoexpression was detected mainly in infiltrating mononuclear cells within lamina propria. High expression of CAT was significantly associated with grade of dysplasia (high grade vs. low grade, $p=0.037$ ). In adenocarcinoma samples, the high level of CAT immunoexpression was significantly correlated with histological grade of tumour (G1 vs. G2 vs. G3, $p=0.001$ ) and depth of invasion (T1 vs. T2 vs. T3 vs. T4, $p=0.003$ ).

Conclusions: Development of colorectal cancer is associated with increased expression of CAT in the stage of adenoma and decreased expression in the stage of adenocarcinoma.
\end{abstract}

\section{Introduction}

It is generally accepted that the gastrointestinal tract, especially the colon, is constantly exposed to reactive oxygen species (ROS) originating from endogenous and exogenous sources [1, 2]. ROS are radicals, ions, or molecules having a single unpaired electron in their outermost shell of electrons; therefore, they are characterised as highly reactive. ROS can be categorised into two groups: free oxygen radicals and non-radical ROS. Among free oxygen radicals the following should be mentioned: superoxide $\left(\mathrm{O}_{2} \cdot\right)$, hydroxyl radical $\left({ }^{\circ} \mathrm{OH}\right)$, nitric oxide (NO*), organic radicals $\left(R^{*}\right)$, peroxyl radicals (ROO*), alkoxyl radicals (RO*), thiol radicals (RS*), sulphonyl radicals (ROS*), thiol peroxyl radicals (RSOO*), and disulphides (RSSR). Non-radical ROS include hydro- gen peroxide $\left(\mathrm{H}_{2} \mathrm{O}_{2}\right)$, singlet oxygen $\left({ }^{1} \mathrm{O}_{2}\right)$, ozone/trioxygen $\left(\mathrm{O}_{3}\right)$, organic hydroperoxides $(\mathrm{ROOH})$, hypochloride $(\mathrm{HOCl})$, peroxynitrite (ONO), nitrosoperoxycarbonate anion $\left(\mathrm{O}=\mathrm{NOOCO}_{2}{ }^{-}\right)$, nitrocarbonate anion $\left(\mathrm{O}_{2} \mathrm{NOCO}_{2}\right)$, dinitrogen dioxide $\left(\mathrm{N}_{2} \mathrm{O}_{2}\right)$, nitronium $\left(\mathrm{NO}_{2}^{+}\right)$, and highly reactive lipid-or carbohydrate-derived carbonyl compounds [3-6].

To keep a steady-state control over ROS production-detoxification and to prevent harmful effects, organisms have evolved defensive systems, e.g. scavenging enzymes [7]. The most significant antioxidant enzymes include superoxide dismutases (SODs) converting superoxide to less reactive $\mathrm{H}_{2} \mathrm{O}_{2}$, catalase (CAT) reducing $\mathrm{H}_{2} \mathrm{O}_{2}$ to water and molecular oxygen, and glutathione peroxidases (GPxs) that eliminate $\mathrm{H}_{2} \mathrm{O}_{2}$ by 
the use of reducing power derived from glutathione [8]. These enzymes are considered as the first-line defence antioxidants and are thought to be highly significant in the prevention of oxidative damage.

\section{Aim}

Therefore, in this work we try to assess immunohistochemical expression of CAT protein not only in adenocarcinoma patients but also in precancerous lesions including tubular, villous, and tubulovillous adenomas.

\section{Material and methods}

\section{The group of patients}

This study was performed on resected specimens obtained from 122 patients who had undergone surgical resection for primary sporadic colorectal cancer, and from 120 patients who had undergone colonoscopy at the Municipial Hospital in Jaworzno (Poland). All the specimens were obtained with the consent of the patients. In all cases, an experienced pathologist reviewed the haematoxylin and eosin $(\mathrm{H}+\mathrm{E})$ slides of the adenomas or primary tumours to confirm the pathological features.

The subject population of colorectal cancer patients comprised 60 men and 62 women. The tumours of the patients were classified histopathologically as adenocarcinoma according to the WHO grading system: grade $1-61$ patients; grade $2-35$ patients; and grade $3-26$ patients.

The population of patients with adenoma comprised 49 men and 71 women. The adenomatous polyps were classified as tubular adenomas - 46 patients; villous adenomas - 37 patients; and tubule - villous adenomas 47 patients.

The design of the study was approved by the ethical committee of the Jerzy Kukuczka Academy of Physical Education in Katowice. The study was supported by grant KNW-1-043/N/5/0 of the Medical University of Silesia.

\section{Immunohistochemistry of catalase protein}

Paraffin-embedded, $4 \mu \mathrm{m}$-thick tissue sections were stained for rabbit polyclonal anti-CAT antibody obtained from GeneTex (cat. no. GTX110704). Deparaffinisation of all sections was performed through a series of xylene baths, and rehydration was performed through graded alcohol. To retrieve the antigenicity, tissue sections were treated three times with microwaves in a $10 \mathrm{mM}$ citrate buffer ( $\mathrm{pH}$ 6.0) for 5 min each. Subsequently, antigen retrieval sections were incubated with rabbit polyclonal anti-CAT antibody (final dilution 1 : 600). The En-Vision method (Dako En-Vision Kit/Alkaline Phosphatase detection system) was used according to the manufacturer's instructions. The bound primary antibody was detected using the New Fuchsin Substrate system (DAKO A/S).

\section{Immunohistochemical analysis}

We graded the immunoreactivity by using a semiquantative approach. Immunohistochemical reaction for CAT was classified into four groups according to the intensity of immunohistochemical reaction: 0 - negative, 1 - weak, 2 - moderate, and 3 -strong. The intensity of immunohistochemical reaction in the inflammatory cells of lamina propria was described as strongly positive. Diffuse staining with the staining intensity weaker than that of inflammatory cells was characterised as moderately positive. Faint or focal staining was described as weakly positive. Heterogeneity was defined as the proportion of cancer cells showing a positive reaction to the total number of cancer cells and was graded from 0 to 3 by assessment: 0 demonstrated negative staining, 1 represented less than $10 \%, 2$ represented $10-50 \%$, and 3 represented more than $50 \%$ of cancer cells with positive reaction. The results of intensity of staining and heterogeneity were combined and scored as follows: 0 represented negative, 1 and 2 represented low, 3 and 4 represented moderate, and 5 and 6 represented high expression.

\section{Statistical analysis}

The relationship between CAT expression and clinicopathological variables was examined by R: A language and Environment for Statistical Computing (R Core Team, Vienna, Austria) using Pearson's $\chi^{2}$ test. The accepted level of statistical significance was $p<0.05$.

\section{Results}

In colorectal mucosa without any pathological changes CAT was predominantly localised in infiltrating mononuclear cells of lamina propria. Positive reaction was detected also in fibroblast-like cells, which were scattered around the crypts. In those cells immunoexpression of CAT was characterised as strong (Figure $1 \mathrm{~A}$ ). Importantly, some fibroblast-like cells demonstrated also weak expression. In cells of the crypts the intensity of CAT expression was described as weak. Weak expression was detected also around blood vessels (Figure $1 \mathrm{~A}$ ).

In adenoma samples strong immunoexpression was detected in infiltrating mononuclear cells within lamina propria. The scattered fibroblast-like cells localised mainly in the close vicinity of changed crypts showed positive strong immunoexpression as well. In neoplastic cells moderate staining appeared confined to the luminal side of the cytoplasm (Figures 1 B-D).

High expression of CAT was significantly associated with grade of dysplasia (high grade vs. low grade, $p=0.037$ ) (Table I). 

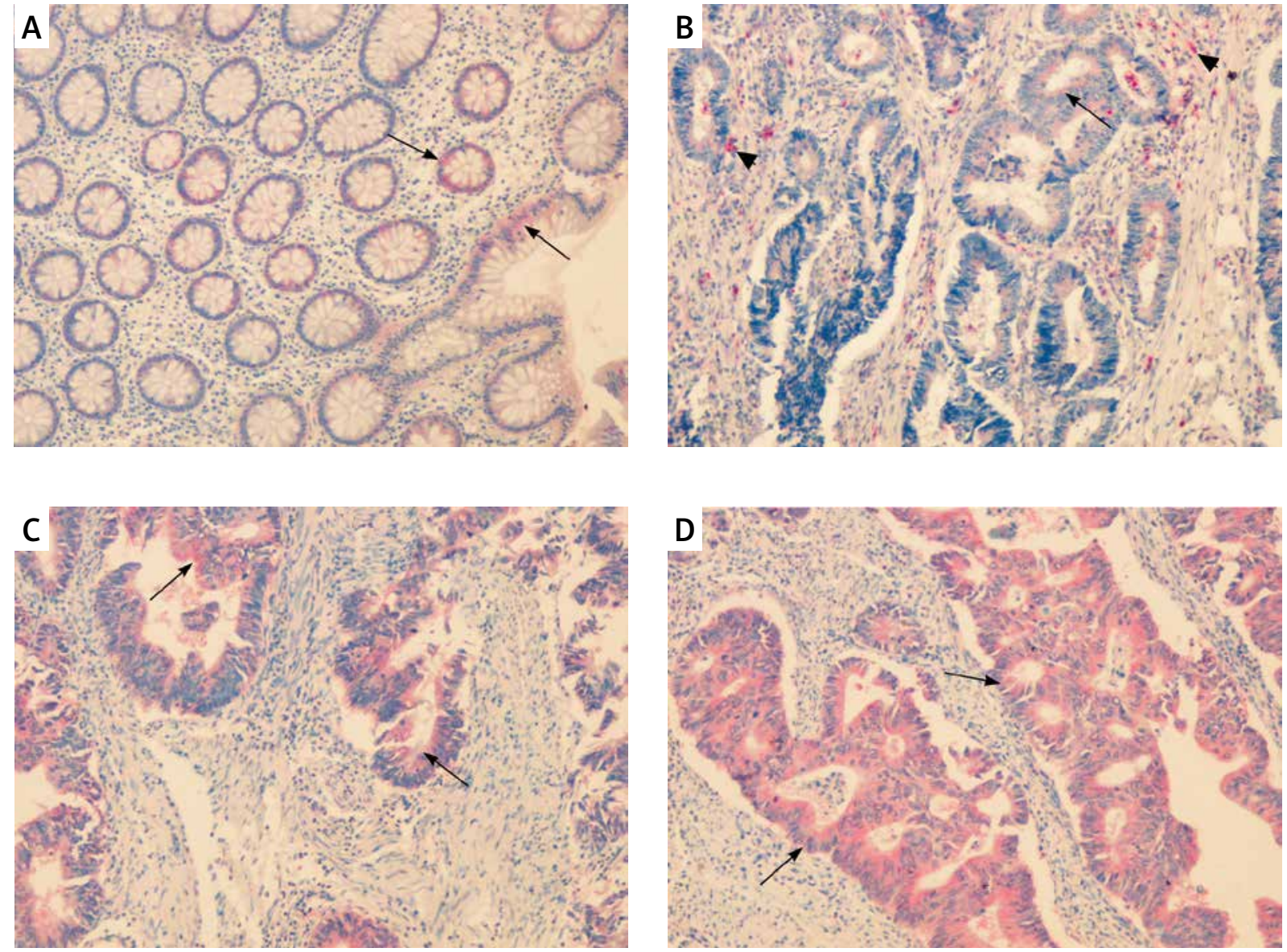

Figure 1. Immunoexpression of catalase (CAT) in colorectal adenomas and adenocarcinomas. A - CAT immunoexpression in cells of lamina propria (red arrows), fibroblast-like cells around the crypts (black arrows) and walls of blood vessels (arrowhead) in healthy colorectal tissue. B, C - CAT immunoexpression in samples of tubular adenomas with low-grade dysplasia. Positive reaction was detected in cells of lamina propria (red arrows) and fibroblast-like cells around the crypts (black arrows). CAT immunoreactivity was also demonstrated in apical parts of the crypts (arrowhead). D - CAT immunoexpression in tubule- villous adenomas with high grade of dysplasia was demonstrated in cells of lamina propria (red arrows) and apical parts of the crypts (arrowhead)

In adenocarcinoma samples, expression of CAT was detected in cytoplasm of stromal and cancer cells. Expression in cancer cells was characterised as moderate or weak, whereas expression in stromal cells was described as strong.

High expression of CAT was significantly correlated with histological grade of tumour (G1 vs. G2 vs. G3, $p=0.003$ ) and depth of invasion (T1 vs. T2 vs. T3 vs. T4, $p=0.033$ ) (Table II).

\section{Discussion}

The increased localised ROS in cancer cells needs to be buffered from reaching a level that incurs cellular damage [3]. An increasing body of evidence points to a prominent role of $\mathrm{H}_{2} \mathrm{O}_{2}$ as one of the most significant
ROS in cancer pathogenesis. Recent data suggest that it may cross cellular membranes through specific members of the aquaporin family. In addition to the mitochondria, $\mathrm{H}_{2} \mathrm{O}_{2}$ might be generated also in peroxisomes. In these organelles, superoxide and $\mathrm{H}_{2} \mathrm{O}_{2}$ are generated through xanthine oxidase in the peroxisomal matrix and peroxisomal membranes [3-6] $\mathrm{H}_{2} \mathrm{O}_{2}$ has been reported to participate in regulation of cell proliferation and induction of the transformed phenotype. For example, when human CAT was expressed in Nox1-expressing NIH 3 T3 fibroblasts, those cells reverted to a normal appearance and tumour was no longer produced in athymic mice [9-16]. Targeted delivery of galactosylated CAT with either 3,5-di(ethylamino-2,2-bisphosphono) benzoic acid (Bip) or polyethylene glycol (PEG) were ef- 
fective in inhibiting bone metastasis of tumour-bearing mice [17]. These findings suggest that CAT is the main antioxidant enzyme, which regulate the level of $\mathrm{H}_{2} \mathrm{O}_{2}$ and may contribute to cancer metastasis. Nevertheless, most malignancies have been shown to contain low levels of CAT, which may be due to the impairment of peroxisomal biogenesis in malignant cells. Given that peroxisomes are usually decreased in cancerous tissues, CAT might also be expressed in other parts of the cell, for example in the cytoplasm and mitochondria [18, 19]. In a study by Jaruga et al. CAT activity was lower in lung carcinoma when compared with normal tissue [20]. Coursin et al. investigated immunoreactivity of antioxidant enzymes in human lung carcinoma and found that CAT was negative in the neoplastic cells [21]. Kwei et al. demonstrated the same down-regulation of CAT expression in the squamous cell carcinomas generated using a mouse three-stage carcinogenesis model [22]. Down-regulated CAT expression has also been reported in ascites tumour cells, Morris hepatomas, Lewis lung carcinomas, and tumourigenic hamster kidney cells as compared to their respective normal cell types [13]. These observations are consistent with a study by Sun et al., who showed that immortalisation and transformation of mouse liver cells with SV40 (simian virus 40) resulted in a decrease in CAT expression contributing to oncogenesis by enhanced ROS production in transformed cells [23]. Finch et al. demonstrated that the loss of CAT expression is in part responsible for the enhanced malignant potential of the $6 \mathrm{M} 90$ cell line. In contrast, increased expression of CAT inhibited proliferation and tumour formation in the malignant $6 \mathrm{M} 90$ keratinocyte cell line at least in part through the EGF-R pathway. Interestingly, the parental line with CAT activ-

Table I. The correlation between CAT immunoexpression and clinicopathological variables in colorectal adenoma patients

\begin{tabular}{|c|c|c|c|c|c|c|c|c|c|c|}
\hline \multirow{4}{*}{$\begin{array}{l}\text { Variables } \\
\text { Age: }\end{array}$} & \multirow{4}{*}{$\begin{array}{c}\text { Total } \\
\text { number } \\
\text { of cases }\end{array}$} & \multicolumn{8}{|c|}{ Expression status } & \multirow[t]{3}{*}{$P$-value } \\
\hline & & \multicolumn{8}{|c|}{ Number of cases (\%) } & \\
\hline & & \multicolumn{2}{|c|}{ Negative } & \multicolumn{2}{|c|}{ Low } & \multicolumn{2}{|c|}{ Moderate } & \multicolumn{2}{|c|}{ High } & \\
\hline & & & & & & & & & & 0.130 \\
\hline$<50$ & 52 & 10 & $19 \%$ & 15 & $29 \%$ & 10 & $19 \%$ & 17 & $33 \%$ & \\
\hline$\geq 50$ & 68 & 10 & $15 \%$ & 20 & $29 \%$ & 25 & $37 \%$ & 13 & $19 \%$ & \\
\hline \multicolumn{10}{|l|}{ Gender: } & 0.089 \\
\hline Male & 49 & 8 & $16 \%$ & 14 & $29 \%$ & 11 & $22 \%$ & 16 & $33 \%$ & \\
\hline Female & 71 & 12 & $17 \%$ & 21 & $30 \%$ & 24 & $34 \%$ & 14 & $20 \%$ & \\
\hline \multicolumn{10}{|l|}{ Location: } & 0.785 \\
\hline Proximal colon & 43 & 8 & $19 \%$ & 10 & $23 \%$ & 15 & $35 \%$ & 10 & $23 \%$ & \\
\hline Distal colon & 39 & 6 & $15 \%$ & 14 & $36 \%$ & 11 & $28 \%$ & 8 & $21 \%$ & \\
\hline Rectum & 38 & 6 & $16 \%$ & 11 & $29 \%$ & 9 & $24 \%$ & 12 & $32 \%$ & \\
\hline \multicolumn{10}{|c|}{ Inflammatory infiltrate: } & 0.452 \\
\hline Weak & 45 & 10 & $22 \%$ & 14 & $31 \%$ & 10 & $22 \%$ & 11 & $24 \%$ & \\
\hline Strong & 75 & 10 & $13 \%$ & 21 & $28 \%$ & 25 & $33 \%$ & 19 & $25 \%$ & \\
\hline \multicolumn{10}{|c|}{ Degree of dysplasia: } & 0.037 \\
\hline Low grade & 50 & 10 & $20 \%$ & 15 & $30 \%$ & 8 & $16 \%$ & 17 & $34 \%$ & \\
\hline High grade & 70 & 10 & $14 \%$ & 20 & $29 \%$ & 27 & $39 \%$ & 13 & $19 \%$ & \\
\hline \multicolumn{10}{|c|}{ Histological type of adenoma: } & 0.697 \\
\hline Tubular & 47 & 7 & $15 \%$ & 14 & $30 \%$ & 17 & $36 \%$ & 9 & $19 \%$ & \\
\hline Villous & 36 & 6 & $17 \%$ & 10 & $28 \%$ & 11 & $31 \%$ & 9 & $25 \%$ & \\
\hline Tubulo-villous & 37 & 7 & $19 \%$ & 11 & $30 \%$ & 7 & $19 \%$ & 12 & $32 \%$ & \\
\hline
\end{tabular}


Table II. The correlation between catalase immunoexpression and clinicopathological variables in colorectal adenocarcinoma patients

\begin{tabular}{|c|c|c|c|c|c|c|c|c|c|c|}
\hline \multirow[t]{3}{*}{ Variables } & \multirow{3}{*}{$\begin{array}{c}\text { Total } \\
\text { number } \\
\text { of cases }\end{array}$} & \multicolumn{8}{|c|}{ Expression status } & \multirow[t]{3}{*}{$P$-value } \\
\hline & & \multicolumn{8}{|c|}{ Number of cases (\%) } & \\
\hline & & \multicolumn{2}{|c|}{ Negative } & \multicolumn{2}{|c|}{ Low } & \multicolumn{2}{|c|}{ Moderate } & \multicolumn{2}{|c|}{ High } & \\
\hline \multicolumn{10}{|l|}{ Age: } & 0.372 \\
\hline$<50$ & 61 & 7 & $11 \%$ & 9 & $15 \%$ & 17 & $28 \%$ & 28 & $46 \%$ & \\
\hline$\geq 50$ & 61 & 3 & $5 \%$ & 13 & $21 \%$ & 13 & $21 \%$ & 32 & $52 \%$ & \\
\hline \multicolumn{10}{|l|}{ Gender: } & 0.903 \\
\hline Male & 60 & 4 & $7 \%$ & 11 & $18 \%$ & 16 & $27 \%$ & 29 & $48 \%$ & \\
\hline Female & 62 & 6 & $10 \%$ & 11 & $18 \%$ & 14 & $23 \%$ & 31 & $50 \%$ & \\
\hline \multicolumn{10}{|c|}{ Size of primary tumour: } & 0.804 \\
\hline$<5 \mathrm{~cm}$ & 63 & 6 & $9 \%$ & 10 & $16 \%$ & 17 & $27 \%$ & 30 & $48 \%$ & \\
\hline$\geq 5 \mathrm{~cm}$ & 59 & 4 & $68 \%$ & 12 & $20 \%$ & 13 & $22 \%$ & 30 & $51 \%$ & \\
\hline \multicolumn{10}{|c|}{ Location of tumour: } & 0.555 \\
\hline Proximal colon & 37 & 5 & $13 \%$ & 7 & $19 \%$ & 7 & $19 \%$ & 18 & $49 \%$ & \\
\hline Distal colon & 37 & 4 & $11 \%$ & 7 & $19 \%$ & 9 & $24 \%$ & 17 & $46 \%$ & \\
\hline Rectum & 48 & 1 & $2 \%$ & 8 & $17 \%$ & 14 & $29 \%$ & 25 & $52 \%$ & \\
\hline \multicolumn{10}{|l|}{ Histological grade: } & 0.003 \\
\hline G3 & 26 & 2 & $8 \%$ & 9 & $35 \%$ & 5 & $19 \%$ & 10 & $38 \%$ & \\
\hline $\mathrm{G} 2$ & 35 & 6 & $17 \%$ & 9 & $26 \%$ & 5 & $14 \%$ & 15 & $43 \%$ & \\
\hline G1 & 61 & 2 & $3 \%$ & 4 & $7 \%$ & 20 & $33 \%$ & 35 & $57 \%$ & \\
\hline \multicolumn{10}{|l|}{ Depth of invasion: } & 0.033 \\
\hline $\mathrm{T} 1$ & 41 & 2 & $5 \%$ & 1 & $2 \%$ & 10 & $24 \%$ & 28 & $68 \%$ & \\
\hline $\mathrm{T} 2$ & 32 & 2 & $6 \%$ & 6 & $19 \%$ & 10 & $31 \%$ & 14 & $44 \%$ & \\
\hline T3 & 22 & 2 & $9 \%$ & 6 & $27 \%$ & 5 & $23 \%$ & 9 & $41 \%$ & \\
\hline $\mathrm{T} 4$ & 27 & 4 & $15 \%$ & 9 & $33 \%$ & 5 & $19 \%$ & 9 & $33 \%$ & \\
\hline \multicolumn{10}{|c|}{ Lymphovascular invasion: } & 0.118 \\
\hline Positive & 75 & 4 & $5 \%$ & 10 & $13 \%$ & 20 & $27 \%$ & 41 & $55 \%$ & \\
\hline Negative & 47 & 6 & $13 \%$ & 12 & $26 \%$ & 10 & $21 \%$ & 19 & $40 \%$ & \\
\hline \multicolumn{10}{|c|}{ Regional LN involvement: } & 0.470 \\
\hline N2 & 37 & 5 & $14 \%$ & 7 & $19 \%$ & 7 & $19 \%$ & 18 & $49 \%$ & \\
\hline N1 & 38 & 5 & $13 \%$ & 7 & $18 \%$ & 9 & $24 \%$ & 17 & $45 \%$ & \\
\hline NO & 47 & 1 & $2 \%$ & 7 & $15 \%$ & 14 & $30 \%$ & 25 & $53 \%$ & \\
\hline
\end{tabular}

ity of $7 \mathrm{Amol} / \mathrm{min} / \mathrm{mg}$ protein was tumourigenic while the cell line MTOC2 with the CAT transgene and CAT activity of $40 \mathrm{Amol} / \mathrm{min} / \mathrm{mg}$ were characterised by low tumourigenicity [24].
In our study we used a large set of colorectal adenomas and adenocarcinomas to assess the expression of CAT at the protein level by the use of immunohistochemistry. To our knowledge, no previous study has 
assessed the clinical significance of CAT protein expression in colorectal neoplasia. Both in adenomas and adenocarcinomas CAT immunoexpression has been detected mainly in infiltrating mononuclear cells of lamina propria or cancer stoma. Nevertheless, expression of CAT has also been observed in cancerous cells, especially in apical parts of the cells. In comparison to controls, in adenoma samples the expression of CAT protein was upregulated. In adenomas with a high degree of dysplasia most samples showed a moderate level of CAT protein expression (about 39\% of patients). In contrast, in adenomas with low degree of dysplasia $34 \%$ of samples revealed high level of CAT expression, and interestingly 30\% demonstrated low level of immunoreactions. In comparison to adenoma samples, in cancer tissues, expression of CAT protein was decreased. Also in those samples, positive reaction was detected mainly in cells of cancer stroma. However, weak expression of CAT has also been demonstrated in cancerous cells. Interestingly, we did not observe any correlation between expression status and type of adenoma. We mention this because it is generally accepted that villous adenoma possess the highest capacity to transform into cancer.

In cancer patients CAT immunoexpression was significantly correlated with histological grade of tumour and depth of tumour invasion. Strong reaction was a characteristic feature of $\mathrm{G} 1$ tumours whereas weak immunoexpression was described mainly in $\mathrm{G} 3$ tumours. Furthermore, as mentioned above, the depth of tumour invasion was also a significant feature. T1 tumours were mainly characterised by strong immunoexpression of CAT, in contrast to T3 and T4, in which cells were mainly described by weak expression.

The results of our study concur with the study by Skrzydlewska et al. These researches revealed the highest increase in activity of $\mathrm{Cu}, \mathrm{Zn}-\mathrm{SOD}, \mathrm{HSH}-\mathrm{Px}$, and GSS$\mathrm{RG}-\mathrm{R}$ as well as decrease in CAT activity $(p<0.001)$ in G3-grade adenocarcinoma and mucinous adenocarcinoma as well as in clinical IV stage of colorectal cancer $[25,26]$. In contrast, expression of another antioxidant enzyme MnSOD in colorectal cancer samples was increased [27]. It seems that decreased activity of CAT in cancerous cells leads to accumulation of $\mathrm{H}_{2} \mathrm{O}_{2}$, which is responsible for damage of DNA and cell death. Therefore, the combination of increased expression of MnSOD and decreased expression of CAT in colorectal cancer cells may result in enhanced production of $\mathrm{H}_{2} \mathrm{O}_{2}$ and decreased detoxification of this compound. Probably the high level of MnSOD and decreased activity of CAT may create an antiapoptotic environment, which is especially susceptible to high frequency of mutations $[27,28]$.

The reason for decreased expression of CAT in neoplastic cells remains puzzling, but it seems that prolonged exposure to ROS is responsible for downregulation of CAT expression by hypermethylation of CAT promoter [28, 29]. Additionally, in such regulation of CAT expression, transcription factors seem also to be involved. The Protein Kinase B (PKB/Akt)/Forkhead Box O (FoxO) transcription factors pathway is probably the best-known regulator of CAT expression [30, 31]. Indeed, FoxO3a has been reported to bind to the rat CAT promoter and in addition the transactivating activity of this transcription factor is negatively regulated by the serine/threonine kinase Akt [31]. Interestingly, it has been demonstrated that CAT expression in human MCF-7 breast cancer cells is repressed by the PI3K/Akt/ mTOR signalling pathway while $\mathrm{FoxO} 3$ seems not to play a significant role in this gene regulation [32]. Limited information is connected with the mechanism of CAT promoter regulation including the regulatory mechanism involved in CAT expression in cancer cells. Transcription factors, such as Nuclear Factor Y (NFY), Specificity protein 1 (Sp1), Peroxisome proliferator-activated receptor gamma (PPAR $\gamma$ ), Forkhead box protein $\mathrm{M} 1$ (FoxM1), and POU domain class 2 transcription factor 1 (POU2F1/Oct-1), have recently been reported to bind the human CAT promoter and probably regulate transcription of CAT gene [33]. Glorieux et al. showed that the AP-1 family member JunB and retinoic acid receptor alpha (RAR $\alpha$ ) mediate CAT transcriptional activation and repression, respectively, by controlling chromatin remodelling through a histone deacetylases-dependent mechanism. This regulatory mechanism plays a critical role in redox adaptation to chronic exposure to $\mathrm{H}_{2} \mathrm{O}_{2}$ in breast cancer cells [33]. It must be noted that in some cancers, expression of CAT has been upregulated. In mesothelioma patients and in rat glioma cells the CAT protein level was increased conferring cellular protection against epirubicin and ionising radiation $\left({ }^{137} \mathrm{Cs} \gamma\right.$-rays) respectively $[34,35]$. Increased CAT expression has also been observed in tumours from patients with gastric carcinoma, skin cancer, and chronic myeloid leukaemia and in human $\mathrm{HL}-60$ cancer cells rendered resistant to chronic exposure to $\mathrm{H}_{2} \mathrm{O}_{2}$ [36-38]. The high level of CAT expression was also a characteristic feature of several human cancer cell lines including gastric, oral, pancreatic, bladder cancer cells exposed to cisplatin, ascorbic acid, bleomycin, gemcitabine, mitomycin C, hormonal therapy, and ionising radiation [13]. Gupta et al. showed that high levels of ROS and low levels of catalase may increase cancer progression, which suggests that catalase may function as a tumour suppressor [39]. Low catalase expression in tumours compared to non-tumour tissues could serve as a valuable predictor of poor survival in patients with advanced HCC, and enhancement of cata- 
lase expression in tumours could be a useful therapeutic strategy for the treatment of HCC patients [40].

This study concerns only histochemical determination without any functional attempt. The direct measurement of reactive oxygen species (ROS) mentioned in the text in the samples collected from surgery and colonoscopy was not performed.

\section{Conflict of interest}

The authors declare no conflict of interest.

\section{References}

1. Bhattacharyya A, Chattopadhyay R, Mitra S, Crowe SE. Oxidative stress: an essential factor in the pathogenesis of gastrointestinal mucosal disease. Physiol Rev 20014; 94: 329-54.

2. Valko M, Leibfritz D, Moncol J, et al. Free radicals and antioxidants in normal physiological functions and human disease. Int J Biochem Cell Biol 2007; 39: 44-84.

3. Galadari S, Rahman A, Pallichankandy S, Thayyullathil F. Reactive oxygen species and cancer paradox: to promote or to suppress? Free Radic Biol Med 2017; 104: 144-64.

4. Piecuch A, Brzozowa-Zasada M, Dziewit B, et al. Immunohistochemical assessment of mitochondrial superoxide dismutase (MnSOD) in colorectal premalignant and malignant lesions. Gastroenterology Rev 2016; 11: 239-46.

5. Liou GY, Storz P. Reactive oxygen species in cancer. Free Radic Res 2010; 44: 479-96.

6. Yang Y, Karakhanova S, Werner J, Bazhin AV. Reactive oxygen species in cancer biology and anticancer therapy. Curr Med Chem 2013; 20: 3677-92.

7. Glasauer A, Chandel NS. Targeting antioxidants for cancer therapy. Biochem Pharmacol 2014; 92: 90-101.

8. Genestra M. Oxyl radicals, redox-sensitive signaling cascades and antioxidants. Cell Signal 2007; 19: 1807-19.

9. Netto LE, Antunes F. The role of peroxiredoxin and thioredoxin in hydrogen peroxide sensing and in signal transduction. Mol Cells 2016; 39: 65-71.

10. Mehrabi S, Wallace L, Cohen S, et al. Differential measurements of oxidatively modified proteins in colorectal adenopolyps. Int J Clin Med 2015; 6: 288-99.

11. Wang Z, Li S, Cao Y, et al. Oxidative stress and carbonyl lesions in ulcerative colitis and associated colorectal cancer. Oxid Med Cell Longev 2016; 2016: 9875298.

12. Gorrini C, Harris IS, Mak TW. Modulation of oxidative stress as an anticancer strategy. Nat Rev Drug Discov 2013; 12: 931-47.

13. Glorieux C, Zamocky M, Sandoval JM, et al. Regulation of catalase expression in healthy and cancerous cells. Free Rad Biol Med 2015; 87: 84-97.

14. Nishikawa M, Hashida M, Takakura Y. Catalase delivery for inhibiting ROS-mediated tissue injury and tumor metastasis. Adv Drug Deliv Rev 2009; 61: 319-26.

15. Nishikava M. Reactive oxygen species in tumor metastasis. Cancer Lett 2008; 266: 53-9.
16. Arnold RS, Shi J, Murad E, et al. Hydrogen peroxide mediates the cell growth and transformation caused by mitogenic oxidase Nox-1. Proc Natl Acad Sci USA 2001; 98: 5550-5.

17. Zheng Y, Nishikawa M, Ikemura M, et al. Inhibition of experimental pulmonary metastasis by controlling biodistribution of catalase in mice. Int J Cancer 2002; 99: 474-9.

18. Nordgren M, Fransen M. Peroxisomal metabolism and oxidative stress. Biochimie 2014; 98: 56-62.

19. Wang B, Van Veldhoven PP, Brees C, et al. Mitochondria are targets for peroxisome-derived oxidative stress in cultured mammalian cells. Free Radic Biol Med 2013; 65: 882-94.

20. Jaruga P, Zastawny TH, Skokowski J, et al. Oxidative DNA base damage and antioxidant enzyme activities in human lung cancer. FEBS Letters 1994; 341: 59-64.

21. Coursin DB, Cihla HP, Sempf J, et al. An immunohistochemical analysis of antioxidant and glutathione S-transferase enzyme levels in normal and neoplastic human lung. Histol Histopathol 1996; 11: 851-60.

22. Kwei KA, Finch JS, Thompson EJ, Bowden GT. Transcriptional repression of catalase in mouse skin tumor progression. Neoplasia 2004; 6: 440-8.

23. Sun Y, Colburn NH, Oberley LW. Depression of catalase gene expression after immortalization and transformation of mouse liver cells. Carcinogenesis 1993; 14: 1505-10.

24. Finch JS, Tome ME, Kwei KA, Bowden GT. Catalase reverses tumorigenicity in a malignant cell line by an epidermal growth factor receptor pathway. Free Radic Biol Med 2006; 40: 863-75.

25. Skrzydlewska E, Stankiewicz A, Sulkowska M, et al. Antioxidant status and lipid peroxidation in colorectal cancer. J Toxicol Environ Health 2001; 64: 213-22.

26. Skrzydlewska E, Sulkowski S, Koda M, et al. Lipid peroxidation and antioxidant status in colorectal cancer. World J Gastroenterol 2005; 11: 403-6.

27. Piecuch A, Brzozowa-Zasada M, Dziewit B, et al. Immunochistochemical assesment of mitochondria superoxide dismutase (MnSOD) in colorectal premalignant and malignant lesions. Gastroenterology Rev 2016; 11: 239-46.

28. Min JY, Lim SO, Jung G. Downregulation of catalase by reactive oxygen species via hypermethylation of CpG island II on the catalase promoter. FEBS Lett 2010; 584: 2427-32.

29. Takeuchi T, Nakamaura S, Kayasuga A, et al. Multiple elements for negative regulation of the rat catalase gene expression in dedifferentiated hepatoma cells. J Biochem 2000; 128: 1025-31.

30. Ramaswamy S, Nakamura N, Sansal I, et al. A novel mechanism of gene regulation and tumor suppression by the transcription factor FKHR. Cancer Cell 2002; 2: 81-91.

31. Coomans de Brachene A, Demoulin JB. FOXO transcription factors in cancer development and therapy. Cell Mol Life Sci 2016; 73: 1159-72.

32. Glorieux C, Auguier J, Dejeans N, et al. Catalase expression in MCF-7 breast cancer cells is mainly controlled by PI3K/ Akt/mTOR signaling pathway. Biochem Pharmacol 2014; 89: 217-23.

33. Glorieux C, Sandoval JM, Fattaccioli A, et al. Chromatin remodeling regulates catalase expression during cancer cell adaptation to chronic oxidative stress. Free Radic Biol Med 2016; 99: 436-50. 
34. Kahlos K, Soini Y, Sormunen R, et al. Expression and prognostic significance of catalase in malignant mesothelioma. Cancer 2001; 91: 1349-57.

35. Smith PS, Zhao W, Spitz DR, Robbins ME. Inhibiting catalase activity sensitizes $36 \mathrm{~B} 10$ rat glioma cells to oxidative stress. Free Radic Biol Med 2007; 42: 787-97.

36. Nenoi M, Ichimura S, Mita K, et al. Regulation of the catalase gene promotor by Sp1, CCAAT-recognizing factors, and a WT1/ Egr-related factor in hydrogen peroxide-resistant HP100 cells. Cancer Res 2001; 61: 5885-94.

37. Zelen I, Djurdjevic P, Popovic S, et al. Antioxidant enzymes activities and plasma levels of oxidative stress markers in B-chronic lymphocytic leukemia patients. J BUON 2010; 15 : 330-6.

38. Gadjeva V, Dimov A, Georgieva N. Influence of therapy on the antioxidant status in patients with melanoma. J Clin Pharm Ther 2008; 33: 179-85.

39. Gupta A, Butts B, Kwei KA, et al.. Attenuation of catalase activity in the malignant phenotype plays a functional role in an in vitro model for tumor progression. Cancer Lett 2001; 173: 115-25.

40. Cho Mi Y, Cheong JY, Lim W, et al. Prognostic significance of catalase expression and its regulatory effects on hepatitis $B$ virus $X$ protein $(\mathrm{HBX})$ in $\mathrm{HBV}$ - related advanced hepatocellular carcinomas. Oncotarget 2014; 5: 12233-46.

Received: 2.10 .2019

Accepted: 26.11 .2019 